\title{
Electrochemical Behaviours of Guanine and Adenine and their Simultaneous Determination using a Three-Dimensional Porous Poly(dopamine)/Reduced Graphene Oxide-Modified Electrode
}

Na Zhang, Wenlin Zhong, Ziqiang Zhang, Yiwen Fan, Deshun Chen, Keying Zhang*

Anhui Key Laboratory of Spin Electron and Nanomaterials; School of Chemistry and Chemical Engineering, Suzhou University, Suzhou, Anhui 234000, China.

*E-mail: zhangky1983@163.com

doi: $10.20964 / 2020.06 .68$

Received: 9 January 2020 / Accepted: 14 February 2020 / Published: 10 May 2020

In this work, a three-dimensional porous poly(dopamine)/graphene-modified electrode was prepared. The modified electrode was characterized by scanning electron microscopy and electrochemical methods. The electrochemical behaviours of guanine and adenine with the modified electrode were investigated by cyclic voltammetry. The experimental results showed that the modified electrode had good electrocatalytic ability for the oxidation of guanine and adenine. Differential pulse voltammetry was used to simultaneously detect guanine and adenine in $0.1 \mathrm{~mol} / \mathrm{L} \mathrm{PBS} \mathrm{(pH} \mathrm{7.0).} \mathrm{The} \mathrm{oxidation} \mathrm{peak}$ currents of guanine and adenine were linear with their concentrations in a range of 1.0-58 $\mu \mathrm{mol} / \mathrm{L}$. The linear regression equation for guanine was $i_{\mathrm{p}}=-1.9501-0.0991 c\left(\mathrm{R}^{2}=-0.9973\right)$ with a detection limit of $0.34 \mu \mathrm{moL}(S / N=3)$, and the linear equation for adenine was $i_{\mathrm{p}}=-1.2005-0.1049 c\left(\mathrm{R}^{2}=-0.9943\right)$ with a detection limit of $0.31 \mu \mathrm{moL}(\mathrm{S} / \mathrm{N}=3)$. In addition, this modified electrode exhibited favourable stability, reproducibility and good anti-interference ability.

Keywords: Graphene, Guanine, Adenine, Poly(dopamine), Modified electrode

\section{FULL TEXT}

(C) 2020 The Authors. Published by ESG (www.electrochemsci.org). This article is an open access article distributed under the terms and conditions of the Creative Commons Attribution license (http://creativecommons.org/licenses/by/4.0/). 